\title{
Design, Development, and Deployment of an Electronic Immunization Registry: A Qualitative Cross-Case Comparison of Experiences from Vietnam, Tanzania, and Zambia
}

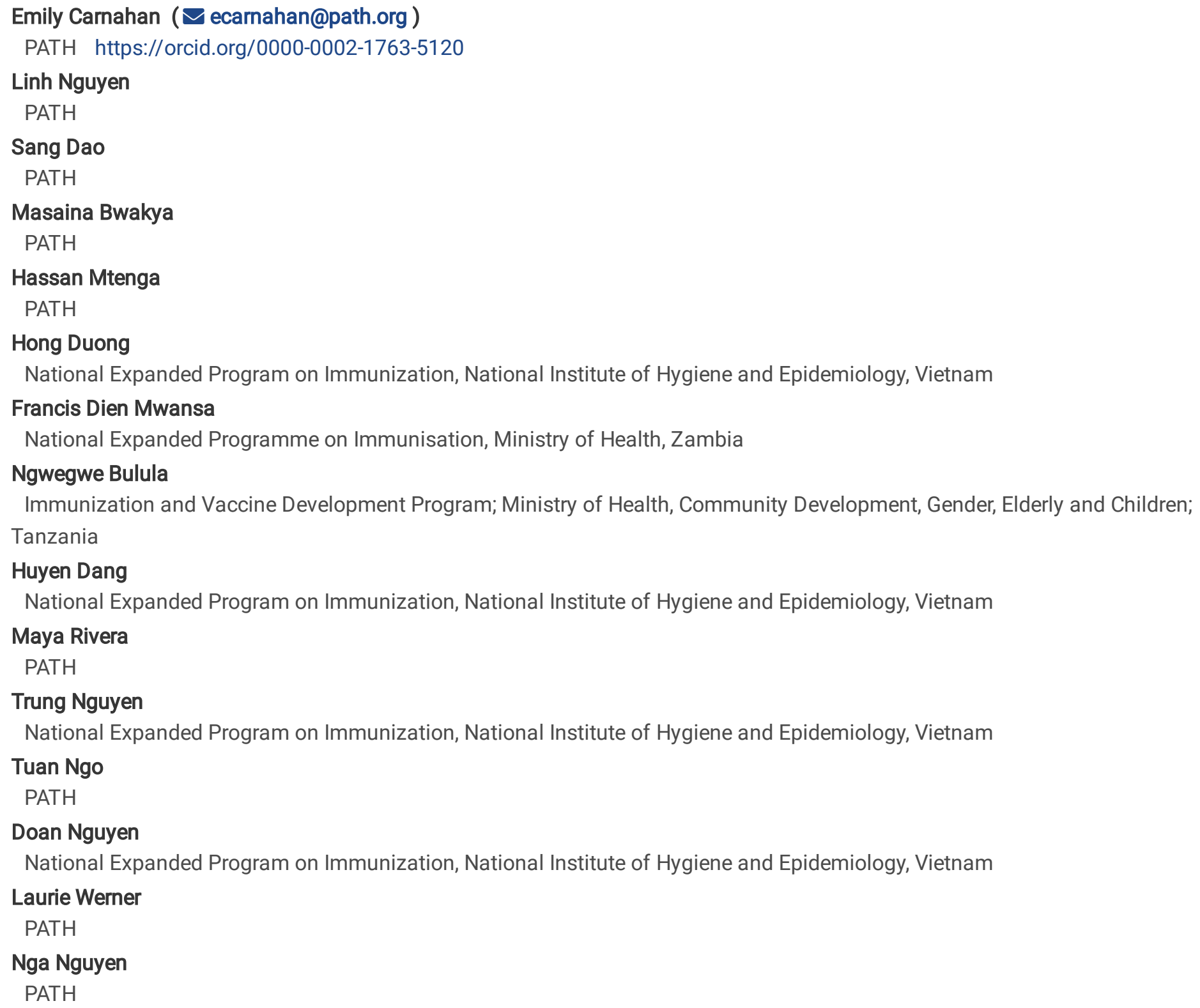

Keywords: electronic immunization registry, immunization information system, immunization, digital health, digital transformation, digital health intervention, mHealth/eHealth

Posted Date: September 1st, 2021

DOI: https://doi.org/10.21203/rs.3.rs-790809/v1 
License: (c) (i) This work is licensed under a Creative Commons Attribution 4.0 International License. Read Full License 


\section{Abstract}

Background: There is growing interest among low- and middle-income countries to introduce electronic immunization registries (EIRs) that capture individual-level vaccine data. While practical EIR guidance documents are available, the real-world implementation experience varies by country. There is an opportunity to learn from countries that have experience implementing EIRs to inform other countries considering the same.

Methods: This qualitative study provides a cross-case comparison of the design, development, and deployment of EIRs in three countries: Vietnam, Tanzania, and Zambia. The countries were selected based on PATH's role in providing technical support to the governments to introduce and scale their EIRs. Through desk review and thematic analyses, we consider findings related to four implementation factors: time, partnerships, financial costs, and technology and infrastructure.

Results: The country cases highlight the multi-year timeline required to implement an EIR at scale. Of the 3 countries, only Vietnam has achieved nationwide scale of the EIR after implementing a series of iterative cycles to pilot and redesign the system over 7 years. In terms of partnerships, all three case countries established interdisciplinary national teams with experience in leadership, technology, and immunization, and incorporated end user perspectives from subnational levels in the EIR design and development. It was important for the national government to play an active role to ensure country ownership and sustainability. Financial investment was necessary for design and development, as well as to maintain the EIR beyond the initial deployment, including all recurring costs for system maintenance, updates, and end user support. Finally, technology and infrastructure were important considerations in the EIR design and choice of equipment in each country, and all 3 countries have a local partner to provide ongoing technical support.

Conclusions: Comparing implementation factors across these cases highlights practical experience and recommendations that complement existing EIR guidance documents. The findings and recommendations from this study can inform other countries considering or in the process of implementing an EIR.

\section{Contributions To The Literature}

- This study documents the experience of designing, developing, and deploying an electronic immunization registry (EIR) across three country contexts: Vietnam, Tanzania, and Zambia.

- The results highlight considerations related to timelines, partnerships, financial costs, and technology and infrastructure.

- The authors provide practical, operational insights and recommendations to country decision-makers who are considering or are in the process of implementing an EIR.

\section{Introduction}

Immunization is an essential health service provided in all countries. In many low- and middle-income countries (LMICs), immunization information has traditionally been captured through paper-based tools at health facilities (1-3). However, as many LMICs are undergoing digital transformation of their health systems, there is an opportunity to leverage digital health solutions for immunization $(2,4)$. One such tool is an electronic immunization registry (EIR), a confidential, computerized, population-based routine system to capture, store, access, and share individual-level, longitudinal health information on vaccine doses administered $(5,6)$. EIRs have been shown to improve immunization practices in LMICs by saving health worker time with automated reporting $(7$, $8)$, improving data quality and use $(3,9-11)$, reducing stockouts (12), and improving immunization coverage (13-15).

There are several resources that provide practical guidance for practitioners to inform the design, development, and deployment of EIRs (16-18). However, the experience varies by country. Practitioners and researchers have called for more implementation research to understand the 'how' and 'why' of digital health implementations $(19,20)$. Moreover, the existing guidance on EIRs does not include specific details implementers often want to know related to timelines, costs, human resources, and other operational considerations. There is an opportunity to learn from countries that have experience implementing EIRs to inform other countries considering the same. 
This study aims to document the practical experience of designing, developing, and deploying an EIR across three country contexts: Vietnam, Tanzania, and Zambia. The results are intended to complement existing EIR guidance documents by providing examples of EIR design and implementation in practice. By doing so, this study aims to provide practical, operational insights to country decision-makers who are considering or are in the process of implementing an EIR.

\section{Methods}

This qualitative study provides a cross-case comparison of the design, development, and deployment of EIRs in three countries: Vietnam, Tanzania, and Zambia.

\section{Conceptual Framework}

This study was guided by a conceptual framework developed by the authors that captures phases of the EIR product development process and key implementation factors across phases (Figure 1). Like any digital solution, the process to develop an EIR includes the phases of design, development, and deployment. Design refers to the initial phase of defining EIR requirements based on user requirements and health system challenges. The development phase refers to building and testing the EIR software based on the predetermined requirements. Finally, the deployment phase refers to the introduction of the EIR system across relevant levels of the health system.

The implementation factors included in the framework were time, partnerships, financial costs, and technology and infrastructure. These implementation factors cut across the phases of design, develop, and deploy. The factors were prioritized based on the authors' experience implementing EIRs and frequently asked questions from other stakeholders interested in learning from the case countries' implementation experience. The factors are consistent with common themes from the existing EIR guidance documents (16-18) and other digital health frameworks (21).

\section{Setting}

PATH is an international non-governmental organization whose mission is to advance health equity (22). The three country settings were selected for this study based on PATH's role in collaborating with and providing technical support to these country governments to introduce and scale their EIRs. Each country immunization context is further described in Table 1.

\section{Intervention}

Each country is in the process of scaling an EIR nationwide, as described below.

\section{Vietnam}

In 2010, PATH began working with NEPI through Project Optimize to improve coverage rates by developing two new systems: ImmReg, a digital registry to manage individual vaccination history, and VaxTrak, a digital vaccine tracking tool (24). ImmReg and VaxTrak grew from a district-level pilot to a central piece of the country's health system, as part of the National Immunization Information System (NIIS) launched nationwide in 2017. Key functions of the NIIS include immunization planning, client management, addressing duplicate records, vaccine administration, stock management, supportive supervision, automated reporting, and SMS reminders for caregivers. The NIIS tracks stock from the national to the commune level and captures vaccination records for all individuals from birth. The NIIS has been shown to increase vaccination coverage and timeliness (13), and as of April 2021, the NIIS includes 24 million client records and has been implemented in 15,044 facilities (representing nearly all facilities nationwide, including all community health centers, but excluding some hospitals and fee-based facilities). In the second half of 2020 the government of Vietnam began transitioning to a paperless immunization system.

\section{Tanzania}


The BID Initiative, funded by the Bill \& Melinda Gates Foundation, launched in 2013 with the aim of improving data quality and data use for immunization (31). Through the BID Initiative, representatives from 10 sub-Saharan African countries co-designed common EIR requirements that became the basis for the EIR requirements in Tanzania and Zambia (32).

Beginning in 2014, Tanzania's MOHCDGEC and PATH collaborated to design and implement an EIR. The first iteration, the Tanzania Immunization Information System (TIIS), was developed in 2014 but due to technical challenges was replaced by a new systemthe Tanzania Immunization Registry (TImR) -in 2016 (33). TImR is an open-source software developed from Open Immunization (OpenIZ) for use on tablets with online and offline functionality (34). TImR captures individual vaccine histories, automates aggregate reports, and tracks stock. TImR has since been integrated with the Vaccine Information Management System, a districtlevel digital tool, providing end-to-end visibility into the vaccine supply chain (35). TImR was rolled out to facilities as part of a larger package of interventions that focused on data quality and data use (31). From 2018-2019, one region, Tanga, (359 facilities) transitioned to completely paperless reporting. Mwanza (328 facilities) and Kilimanjaro (306 facilities) regions are expected to transition to paperless reporting in Q2 2021. As of April 2021, TImR includes 1.9 million client records and has been implemented in 3,736 of approximately 6,000 facilities across 15 of 26 regions in mainland Tanzania.

\section{Zambia}

Like Tanzania, Zambia was also selected to implement a package of immunization data quality and use interventions through the BID Initiative (31). Beginning in 2015, PATH and Zambia's MoH partnered to develop an EIR. The initial system, built on the DHIS2 Tracker platform, did not meet certain requirements for immunization and entailed a lengthy development timeline. In early 2017, Zambia turned to the Open Smart Register Platform (OpenSRP) for its EIR (36). The resulting Zambia Electronic Immunization Registry (ZEIR) supports nurse workflows for child vaccination and growth monitoring. Key features of ZEIR include a unique login for health workers in the same facility, a simple birth registration form that resembles the paper cards mothers bring with them to clinic visits, and data on growth monitoring and several other metrics, to mirror nurse workflows and help health workers avoid duplicative data entry. After piloting ZEIR in early 2017, the registry was rolled out across all health facilities that deliver immunization services in Southern Province (31). As of April 2021, ZEIR has been implemented in Southern and Western Provinces, capturing over 170,000 client records across 320 health facilities. There are plans to continue to scale ZEIR to reach all 2,600 health facilities across 9 provinces nationwide.

\section{Data collection and analysis}

To understand the implementation factors across EIR product phases, we employed a multiple case study approach with each country considered a case. A case study approach was chosen to learn from the experience in each country in way that could leverage multiple sources of evidence and explore the complexity across implementation factors and phases.

Data collection and analysis was an iterative process from October 2019 through June 2020. A desk review was conducted to identify relevant documentation, including project reports, communication materials, planning documents, technical guidance documents, and peer-reviewed literature. Existing guidance documents (not country-specific) on implementing EIRs were also reviewed (16-18).

For each country case, we reviewed documents and used an analytic matrix to sort evidence into content domains according to the conceptual framework. Thematic analysis was conducted within each framework domain. Findings were triangulated across documents and the identification of additional documents stopped when saturation was reached (no new themes identified). To synthesize findings across the countries, we conducted cross-case analysis of factors to identify common patterns or positive or negative deviants. Thematic analyses used manual coding. Draft findings were reviewed by relevant stakeholders in each country for validation prior to finalization.

\section{Ethics}


The study procedures were reviewed and received non-research determination by PATH. Study data were stored in an accessrestricted server, only available to study staff for the purpose of data analysis.

\section{Results}

Results are organized by the implementation factors of time, partnerships, financial costs, and technology and infrastructure, with key findings from each country case presented.

\section{Time}

Current EIR guidance documents provide an overview of steps to plan for in the EIR process, but do not include details on timelines associated with each step or the overall process as it can vary widely.

\section{Vietnam}

In Vietnam, it took seven years to fully design, develop, and deploy the EIR from its initial design as part of the Optimize Project beginning in 2010 (24) until it reached nationwide scale in 2017. Over this period, the EIR matured through a series of phased digital health pilots, each of which provided an opportunity for iterative learning and improvement (Table 2).

The initial design phase for ImmReg took 3-4 months to conduct a landscape assessment, collect and document user system requirements, and collaborate with the software developer to finalize the technical specifications. The development phase for ImmReg took another 4 months to develop the software, including user interface testing and case-testing to check the functionality and data accuracy. In comparison, Vaxtrak took approximately 6 months to design and another 6 months to develop, this longer process was due to the more complicated system requirements for vaccine management and reporting. Deployment of the initial versions of ImmReg and Vaxtrak began in 2012 in a limited number of provinces.

From 2013-2014, ImmReg and VaxTrak were upgraded and combined into a single web-based application. Many new functional requirements were added, but the time to develop the requirements documents was minimal (approximately 2 months) because the system workflows, interface, functionalities, architecture, and end-user needs were well understood from the previous implementations. The development of the combined system took approximately one year, and the updated system was deployed beginning in 2014 .

In 2016, the combined system was integrated into the NIIS which saved the NIIS software development team time by integrating the knowledge and technology from the previous pilots. The development of NIIS took approximately 8 months including in-house testing before deploying first in 5 pilot districts and then nationwide. As of 2017, the NIIS has been introduced in all facilities across Vietnam, although support to encourage system uptake, improve data quality, and transition to paperless is ongoing.

\section{Tanzania}

In Tanzania, the EIR requirements were shared in a request for proposal in late 2014 and the first system, TIIS, was chosen. TIIS development was initially planned for 3 months but due to the complexity of the system being developed, it was extended to six months (Table 2). As mentioned above, technical challenges with TIIS emerged during the pilot in Arusha Region which led to the decision to update the requirements and release a revised RFP in February 2016 (37). The OpenIZ system, TImR, was selected in and developed over approximately 9 months in 2016-2017. TImR deployment began in 2017 and the government plans to scale TImR nationwide to all facilities by the end of 2021.

\section{Zambia}

In Zambia, the EIR requirements were shared in a request for proposal in July 2015 and the DHIS2 Patient Tracker software was selected and began development in 2015. Like the Tanzania experience, there were challenges adapting the software to meet the requirements, and development stopped after 10 months in 2016 (38). After refining the requirements, Zambia selected the 
OpenSRP-based ZEIR in early 2017. OpenSRP had already been successfully used for immunization in Pakistan which contributed to the efficient development in Zambia, requiring 3 months of development time for an initial release and 6 months for a nearcomplete version for expanded rollout (39). Deployment began in May 2017 and ZEIR was deployed to 320 facilities in Southern Province by March 2018. An additional 281 facilities in Western province are yet to go live and there are plans to scale ZEIR nationwide.

\section{Partnerships}

EIR guidance documents recommend developing a multidisciplinary team that can oversee all project functions and defining the roles and responsibilities of each participant from the outset (16-18). The guidance also notes that some partners with specific skillsets (e.g., in software development or training) may only be required for certain project phases.

\section{Vietnam}

Beginning in 2010, NEPI, PATH, and WHO partnered to develop ImmReg and VaxTrak. A challenge that surfaced during the initial work in 2010-2012 was that IT professionals lacked immunization expertise, and public health professionals lacked understanding of technical software development terms and processes. A lesson learned was to have "bridging" staff who could improve alignment, for example, including an IT professional with technical expertise on the core project team to improve collaboration with software developers (24).

In 2016, when the NIIS was being re-designed to scale from one province to 63 provinces nationwide, the NIIS Technical Working Group (TWG) was formed. The TWG includes representatives from appropriate agencies with complementary expertise:

- The MoH General Department of Preventive Medicine (GDPM) provides management authority, stakeholder coordination, administration support, and oversight of provincial implementation and policy change.

- The NEPI provides immunization expertise, acting as the technical lead on immunization workflows, corresponding user requirements, and reporting systems.

- Viettel, one of the largest mobile network operators in Vietnam, provides technology expertise to develop and maintain the system.

- PATH provides technical support and facilitates communication between TWG members, serving as the connection between immunization, general health, and technology stakeholders.

All partners bring complementary expertise and have been crucial to the scale-up of the NIIS from design to deployment. Although the TWG partnership has functioned well, there was initially confusion in roles, deliverables, and financial responsibilities which created delays in coordination and implementation (40).

In addition, partners at subnational levels were involved in the design phase to inform system requirements, in the development phase to support testing the system and providing inputs on user experience, and in the deployment phase for training and ongoing mentorship. During design and development, representatives of different end-user roles were included, such as managers, EPI officers, and storekeepers.

\section{Tanzania}

Through the BID Initiative, PATH partnered with the MOHCDGEC. An MOU was signed in September 2014 to formalize the relationship. During the design and development phases, PATH worked closely with the national IVD program, the MoH Information Communication Technology (ICT) Unit, as well as regional and district leadership, particularly in the pilot site, Arusha Region. PATH provided technical oversight and business analysis support, while the $\mathrm{MoH}$ was responsible for testing and ensuring the EIR met the use case requirements.

During the EIR development phase, Mohawk College (Canada) was selected to develop TImR. However, not having the lead developers in-country made communication challenging due to time zone differences and a limited understanding of the local use 
cases. When there were critical system issues, the fixes were often delayed due to the time zone differences and limited capacity outside of the software teams. Mohawk College partnered with an in-country software firm, Softmed, to improve responsiveness and build capacity for ongoing system maintenance and sustainability.

At the subnational level, a User Advisory Group (UAG) provided end-user perspectives on the system requirements and tested the usability of the system during the design and development phases. UAG members included representatives from regional, district, facility, and community levels who support immunization service delivery, supply chain, data collection, or community engagement (41).

Other partners included those in the Inter-agency Coordinating Committee (WHO, UNICEF, and other partners) who monitored EIR progress.

\section{Zambia}

Through the BID Initiative, PATH partnered with the Ministry of Community Development, Mother and Child Health (MDCMCH) and signed an MOU on February 5, 2015 to formalize the relationship. While the EPI unit was under the MDCMCH, the management of information and communication technology (ICT) and M\&E were under the $\mathrm{MoH}$. This structure was challenging to coordinate decision-making between two ministries which led to delays in the EIR design, development, and implementation process. A technical working group was formed in 2015 that included staff from the EPI, M\&E, and ICT units from both ministries which facilitated streamlined decision-making. In 2016, the Mother and Child Health unit shifted to fall under the MoH and a new MOU was signed.

In practice, PATH worked closely with provincial and district leaders in Southern Province, the area selected to pilot the EIR. Like Tanzania, a UAG was established that included district, facility, and community level end users to provide inputs on the system design and development (42). In the EIR development phase, Kenya-based software developer Ona was contracted to develop ZEIR and a local software company, Blue Code, was also contracted to support ongoing maintenance of the system. Like in Tanzania, having a local software partner helped address communication, contextualization, and sustainability challenges in working with a software developer based outside Zambia.

Beginning in 2017, the Catholic Medical Mission Board partnered with the MoH and PATH to deploy ZEIR to nine health facilities in Mwandi District of Western Province (43).

\section{Financial costs}

EIR guidance documents emphasize the need to develop a funding model that can sustain the project through the entire process, including all organizational costs in the short, medium, and long term (16-18).

\section{Vietnam}

During the initial ImmReg design phase, the project team developed a financial model to predict the costs of ImmReg implementation in Vietnam. Utilizing this model, the costs were estimated for scaling to forty provinces with 450 districts and 9,000 communes over a five-year period. The model generated costs for each year at commune, district, and provincial levels. This was an important input to the planning and design of ImmReg.

Since Viettel joined the NIIS TWG, they have provided in-kind services to support the development and deployment of the NIIS. Although Viettel is committed to supporting the NIIS, they have raised the challenge of ongoing investment in infrastructure and human resources (40). The Vietnam $\mathrm{MOH}$ and Viettel are discussing an appropriate mechanism and service fee that will allow Viettel to operate, maintain, and upgrade the system.

During the deployment phase, user feedback resulted in unanticipated costs to update the NIIS and to provide supportive supervision visits to address technical issues. At the beginning of nationwide scale-up, PATH and WHO financed the training-of-

Page $8 / 19$ 
trainer trainings for national, regional, and provincial level staff, as well as training for district staff in 20 provinces. Overall, the pilot phase was longer than planned which resulted in higher costs than originally projected.

In terms of ongoing operational costs, local governments are responsible for covering the cost of maintaining or replacing equipment (PCs, barcode scanners, and printers), conducting refresher trainings, providing supportive supervision, and funding internet or $3 \mathrm{G}$ connectivity. One ongoing cost that was not factored into the original financial model, is the need to update and expand the NIIS server to accommodate the enormity of data as additional children are registered into the system.

\section{Tanzania and Zambia}

When the BID Initiative launched in 2013, there was limited evidence on the cost of designing, developing, and deploying EIRs particularly in low-resource settings. Recognizing this evidence gap, the BID team used a total cost of ownership model to estimate the costs to design, develop, deploy, and maintain EIRs in Tanzania and Zambia. This costing work focused on the costs incurred during the duration of the BID Initiative between 2013 and 2018. The results showed that hardware and rollout costs were the two largest shares of the overall costs (44). However, for each deployment to subsequent regions in Tanzania, costs declined by implementing the learnings gained from previous deployments.

The total annualized cost of developing, deploying and maintaining the EIRs and their related suite of interventions through the BID Initiative was estimated to be between US\$3.30 to \$3.81 per child for the regions in Tanzania and US\$8.46 in Zambia (44). The Zambia estimate is higher in part due to a smaller birth cohort compared to Tanzania. Additionally, a micro-costing study estimated the annual cost savings per facility resulting from the introduction of the BID interventions (including the EIR) as US\$10,236 in Tanzania and \$628 in Zambia, largely driven by health worker time savings in service delivery and reporting (7).

During the deployment phase, there were significant financial cost implications based on the implementation approach used. At the outset in Tanzania, the PATH team led the deployment through a series of visits to health facilities for on-site training. However, this approach was too expensive and technically infeasible to scale and necessitated a new approach whereby PATH staff trained district data use mentors who led the facility-level deployment. The new approach improved country ownership and reduced implementation costs by $10-65 \%$ per district (45).

To encourage sustainability and government ownership, the $\mathrm{MOH}$ in each country began to take over procurement costs toward the end of the BID Initiative project, buying tablets, providing project vehicles, and using government staff for trainings. In both countries the districts are budgeting for ongoing operational costs, like data bundles and tablet replacements, in an increasing fashion. Tanzania has secured Gavi Health System Strengthening funding to continue to scale the EIR and Zambia has secured Gavi funding for an EPI Optimisation Platform (EPI OPT) that includes strengthening ZEIR. In Zambia, a second EPI OPT grant is underway to support scaling ZEIR to additional 281 facilities in 16 districts of Western Province.

\section{Technology and infrastructure}

EIR guidance documents highlight the importance of taking into account the infrastructure needs to inform the selection of and support for a new technology (16).

\section{Vietnam}

In the design phase, the initial ImmReg landscape assessment considered aspects of the technological infrastructure including IT knowledge of health workers, lessons learnt from previous software implementations, and available equipment and connectivity. The results in 2011 showed that commune health centers did not have computers nor internet connectivity, there were limited resources available to purchase computers, and health workers' computer skills were limited but they were comfortable using mobile phones. Based on this, ImmReg and Vaxtrak were designed as stand-alone mobile applications for commune health workers with a web-based interface for the district level where computers were available. However, despite health workers' comfort and access to mobile phones, they were not familiar with downloading and installing new software which created challenges. By 2013-

Page 9/19 
14 when ImmReg and VaxTrak were combined and upgraded, most commune health centers had computers and internet connection, so the combined system was designed as a web-based application.

The deployment phase has required ongoing technical support and system maintenance. The system has required continuous editing to add new vaccines, new variables, or new data queries based on end user feedback. Over time, Vietnam shifted from providing in-person technical support for end users to remote technical support, this has saved time, improved responsiveness, and decreased the number of field trips for the technical team. Currently, remote support includes an artificial intelligence chatbot, a telephone hotline, technical support groups on a popular social media application (Zalo), and trained mentors at each level of the health system. In addition to support from the health system, Viettel has an end-user support network and 24/7 hotline which ensure timely technical support for end users.

\section{Tanzania}

At the outset of the BID Initiative in 2013, eHealth was a national objective and well supported by the President and Minister of health. The $\mathrm{MoH}$ was in the process of establishing an eHealth Steering Committee and eHealth strategy and there was mainly $2 \mathrm{G}$ internet connectivity in most urban places. However, digital literacy was very low particularly among frontline health care workers, most facilities did not have computers, and some facilities were not connected to the national electricity grid nor internet services. The UAG helped to advise on the existing technological infrastructure during the design phase.

The existing infrastructure informed decisions during the design phase to require online and offline functionality and to purchase tablets for most facilities. For facilities without reliable access to electricity, a paper-based version of the EIR was designed that could be scanned at the district level to digitize the data. However, during the pilot phase it was determined the paper-based forms were not feasible, and all facilities received tablets to use the EIR. Those facilities with intermittent electricity also received solar chargers for the tablets.

During the deployment phase, district staff found it challenging to train health care workers due to their varied familiarity and confidence with technology. Another challenge was in purchasing and distributing sufficient data bundles to support tablet connectivity (46). In some cases, there were also challenges with syncing the tablets to the EIR.

Currently, the $\mathrm{MoH}$ team provides ongoing technical support for software development and maintenance, as well as data analysis and use. Immunization staff at each level of the health system provide technical support to end users at lower levels and there are district WhatsApp groups that facility health care workers use to raise issues or troubleshoot.

\section{Zambia}

The UAG in Zambia advised on the technological infrastructure during the EIR design phase. In the pilot region of Southern Province, 144 (48\%) of 302 health facilities were known to have no consistent power source (46). Based on the existing infrastructure during the design phase, the BID Initiative team initially thought that some facilities would need to continue to use improved paper-based registers, however it was later determined that to ensure cost-effectiveness of the EIR all facilities should use the electronic system. Solar chargers were procured for facilities with intermittent electricity.

Like Tanzania, the EIR deployment in Zambia faced challenges resulting from limited technology skills among health workers, difficulty securing data bundles, and inconsistent data syncing (46).

Currently, BlueCode is working with the $\mathrm{MoH}$ to build its capacity for both technical and governance ownership of the project. This entails working closely with the $\mathrm{MoH}$ technical and management team and supporting the $\mathrm{MoH}$ with supervision and training. There are also ongoing iterations to strengthen ZEIR based on user feedback and as mentioned, ZEIR has been integrated with other systems through the EPI OPT.

\section{Discussion}

\section{Principal findings and implications}

Page 10/19 
This study summarizes the experiences across three countries related to key implementation factors-time, partnerships, financial costs, and technology and infrastructure-that influence the design, development, and deployment of EIRs.

The cases highlight the long timeline required to implement an EIR at scale. In Vietnam, it took seven years from the start of Project Optimize to the nationwide introduction of the NIIS. In Tanzania and Zambia, the EIR development process began with the crosscountry collaborative requirements meeting in late 2013, and seven years later both countries are still in the process of scaling the EIR nationwide. Across all three countries, the timeline included multiple system iterations. Particularly in Vietnam, there was a series of iterative cycles to pilot and redesign the system before achieving scale. This may have lengthened the overall timeline, but each iteration provided an opportunity to redesign and learn from the experience (47). Subsequent cycles added more complex requirements, yet the timing for design and development was streamlined due to the ability to build on the existing system.

The protracted timeline for EIR design and development in Tanzania and Zambia was in part because the defined requirements were more advanced than the technology available at the time. Now the technology has advanced and there are multiple EIR platforms countries can choose from. For new countries implementing EIRs, the design and development phases should be streamlined compared to our case countries. For instance, OpenSRP software has been used for EIRs in Pakistan, Zambia, and Kenya, with cost and time savings in each subsequent rollout (39). And the concise set of requirements used to inform the ZEIR development have been packaged and shared as a proposed minimum viable product for other EIR implementations, regardless of software (33). Further, in June 2020, the World Health Organization released a request for proposals to develop a "Digital Accelerator Kit" that outlines software agnostic requirements for an EIR to accelerate implementation (48). These resources will support countries to start from existing software or minimum viable product requirements that can be iteratively adapted or expanded as necessary.

In terms of partnerships, all three case countries established interdisciplinary teams with experience in leadership, technology, and immunization, which is consistent with recommendations in existing EIR guidance documents (16-18). Based on the experience in Vietnam, it is important to put in place an MOU or formal agreement to clarify roles, deliverables, financial responsibilities, and outcomes among this group (40). At the national level, all cases highlight the importance of Ministry of Health (MoH) leadership through all EIR phases to ensure country ownership, sustainability, and alignment with national strategies and standards. At subnational levels, all cases highlight the importance of user-centered design to inform the EIR design and development. In Vietnam this was achieved through an initial landscape assessment to identify critical EIR requirements based on end user needs, and by incorporating user feedback and lessons learned in each system iteration. In Tanzania and Zambia, establishing the UAGs was seen as a successful approach to ensure timely testing and input from end users throughout the system design and development (49).

A key difference in partnership approaches across the cases, is the role of the software developer. In Vietnam, there is a strong public-private partnership where Viettel (mobile network operator) is a formalized member of the TWG and has been actively involved in the EIR design, development, and deployment. This has worked well because Viettel, a state-run organization, has a wellestablished relationship with the government of Vietnam, the MoH has confidence in Viettel's data security, and Viettel can support the connectivity, infrastructure, and business needs of the EIR (40). Alternatively, in Tanzania and Zambia, the primary technology partners were international organizations that were contracted at the outset of the EIR development phase for a term agreement. In this type of partnership, it was important to identify other ways to ensure ongoing operational and management support of the system, for example, contracting with local developer partners. In some countries it may be feasible to strengthen capacity of MoH staff to provide ongoing system support.

The different partnership models also had implications for financial costs of the EIR implementation. Across all case countries, PATH as a technical partner received funding through the Bill \& Melinda Gates Foundation. Vietnam has also received financial support from the United Nations Foundation and GlaxoSmithKline, and Tanzania and Zambia have received funding from Gavi to support their respective EIR implementations. In Vietnam, Viettel absorbs many costs associated with the system itself. Across all cases, the MoH has contributed significant in-kind time. As shown by the BID Initiative costing studies, the rollout strategy used in the EIR deployment phase can have large cost implications. And as noted, leveraging existing software solutions or requirements can also reduce EIR design and development costs. In the field of digital health more broadly, there has been a call for research on the costs associated with implementation of digital tools, particularly their ongoing operational and maintenance costs (20). As more countries introduce EIRs, they should capture their costs to fill this evidence gap and test the hypothesis that there are cost savings from adapting existing systems. 
While not specific to one implementation factor, an emergent cross-cutting theme was the importance of planning for sustainability and scale from the start. Partnerships that promote government ownership and engage end users can foster sustainability. The importance of planning for ongoing financing, technical support, and system maintenance at scale was also highlighted. Another sustainability consideration that surfaced was planning for the transition away from legacy tools, including developing guidance on any criteria that need to be met before making the transition. Other studies have highlighted the burden placed on health workers that are required to use the legacy tools and EIR in parallel $(47,50,51)$.

Table 3 summarizes the recommendations based on the comparison of experiences in Vietnam, Tanzania, and Zambia. Future research should also compare experiences from other country contexts to add to these recommendations, particularly in Latin America where many countries have implemented EIRs (52). The conceptual framework we employed was useful to organize the evidence and identify these recommendations, however, we note from the country cases that the phases of 'design, develop, and deploy' are not linear or mutually exclusive. In addition to the implementation factors considered in this study, other factors like governance and policy could be considered in future studies.

\section{Limitations}

This study focused on three country cases that were not selected to be representative of countries that have introduced EIRs. Instead, the case studies were intended to show a range of experiences and a conceptual framework was used to produce generalizable evidence. Future research could implement a more systematic case selection process with defined criteria to maximize generalizability of the findings from EIR implementations (53). Another limitation is this study considered a subset of implementation factors but taking a wider lens could elicit other findings and recommendations. Finally, the authors acknowledge our participation in the implementation of the EIRs in the case countries. Although this limits the independence of our perspectives, it allows us to draw on our in-depth knowledge of the implementation experience to strengthen the case studies and provide recommendations.

\section{Conclusions}

As there is growing interest across countries in introducing EIRs to support their immunization programs, they can learn from the experiences of Vietnam, Tanzania, and Zambia. Comparing implementation factors-time, partnerships, financial costs, and technology and infrastructure-across these cases highlights practical experience and recommendations that complement existing EIR guidance documents. As more countries introduce EIRs and leverage existing software solutions, we expect to see further streamlining of timelines and financial costs.

\section{Abbreviations}

DHIS2 District Health Information Software 2

DTP diphtheria-tetanus-pertussis vaccine

DVD-MT District Vaccine Management Tool

EIR electronic immunization registry

EPI Expanded Program on Immunization

EPI OPT EPI Optimisation Platform

GDPM General Department of Preventive Medicine

HIA2 Health Information Aggregation 2

ICT Information Communication Technology

IVD Immunization and Vaccine Development 
LMICs low- and middle-income countries

M\&E monitoring and evaluation

MDCMCH Ministry of Community Development, Mother and Child Health

MoH Ministry of Health

MOHCDGEC Ministry of Health, Community Development, Gender, Elderly, and Children

NEPI National Expanded Program on Immunization

NIIS National Immunization Information System

OpenIZ Open Immunization

OpenSRP Open Smart Register Platform

TIIS Tanzania Immunization Information System

TImR Tanzania Immunization Registry

TWG Technical Working Group

UAG user advisory group

WHO World Health Organization

\section{Declarations}

- Ethics approval and consent to participate: This study received non-research determination from PATH's internal review board.

- Consent for publication: Not applicable

- Availability of data and materials: Data sharing is not applicable to this article as no datasets were generated or analyzed during the current study.

- Competing interests: The authors declare that they have no competing interests.

- Funding: BMGF Investment ID OPP 1198325

- Authors' contributions: NN, SD, LN, MR, LW, and EC contributed to the conception and design of the study. EC, SD, LN, and MR led the data acquisition, analysis, and interpretation. EC drafted and led revisions of the manuscript. All authors contributed to the data acquisition and interpretation, supported revisions, and approved the final manuscript.

- Acknowledgements: The authors thank the Bill and Melinda Gates Foundation for providing support for this study and the Governments of Tanzania, Vietnam, and Zambia-and specifically the immunization programs-for their leadership in designing, developing, and deploying the electronic immunization registries (EIRs). In addition, the authors acknowledge the important contributions of others who were involved in implementing the EIRs, including the Technical Working Group members in Vietnam and PATH staff in Tanzania, Vietnam, and Zambia. Finally, the authors thank Celina Kareiva and Celia Lang (PATH staff) for their document review support.

\section{References}

1. Namageyo-Funa A, Samuel A, Bloland P, Macneil A. Considerations for the development and implementation of electronic immunization registries in Africa. Pan Afr Med J. 2018,30:81.

2. Tozzi AE, Gesualdo F, D’Ambrosio A, Pandolfi E, Agricola E, Lopalco P. Can Digital Tools Be Used for Improving Immunization Programs? Front Public Health [Internet]. 2016 Mar 8 [cited 2020 Mar 23],4. Available from: https://www.ncbi.nlm.nih.gov/pmc/articles/PMC4782280/

Page 13/19 
3. Immunization Data: Evidence for Action. A Realist Review of What Works to Improve Data Use for Immunization, Evidence from Low- and Middle-Income Countries. [Internet]. Seattle, WA: PATH, PAHO, 2019 [cited 2020 Jun 2]. Available from:

https://www.technet-21.org/en/library/main/5545-a-realist-review-of-what-works-to-improve-data-use-for-immunization

4. Dumit EM, Novillo-Ortiz D, Contreras M, Velandia M, Danovaro-Holliday MC. The use of eHealth with immunizations: An overview of systematic reviews. Vaccine. 2018 18,36(52):7923-8.

5. World Health Organization. Classification of Digital Health Interventions v1.0 [Internet]. Geneva, Switzerland: WHO, 2018. Available from: http://apps.who.int/iris/bitstream/handle/10665/260480/WHO-RHR-18.06-eng.pdf?sequence=1

6. Freeman VA, DeFriese GH. The challenge and potential of childhood immunization registries. Annu Rev Public Health. 2003,24:227-46.

7. Mvundura M, Giorgio LD, Vodicka E, Kindoli R, Zulu C. Assessing the incremental costs and savings of introducing electronic immunization registries and stock management systems: evidence from the better immunization data initiative in Tanzania and Zambia. The Pan African Medical Journal [Internet]. 2020 Dec 2 [cited 2020 Jun 18],ARTVOL(ARTISSUE). Available from: https://www.panafrican-med-journal.com/content/series/35/1/11/full/

8. PATH. PATH Vietnam and ImmReg: Expanding reach of the immunization registry in Vietnam [Internet]. 2016 Jun. Available from: https://www.path.org/resources/path-vietnam-and-immreg-expanding-reach-of-the-immunization-registry-in-vietnam/

9. Werner L, Seymour D, Puta C, Gilbert S. Three Waves of Data Use Among Health Workers: The Experience of the Better Immunization Data Initiative in Tanzania and Zambia. Global Health: Science and Practice. 2019 Sep 23,7(3):447-56.

10. Kindoli R. BID Initiative Final Evaluation Report: Immunization Data Quality and Use in Tanzania [Internet]. Dar es Salaam, Tanzania: PATH, 2018. Available from: http://bidinitiative.org/wp-content/uploads/BID-Initiative_ME-EndlineReport_Tanzania_FINAL_20August2018.pdf

11. Zulu C. BID Initiative Midline Report, Zambia. PATH, 2018 Apr.

12. Gilbert SS, Bulula N, Yohana E, Thompson J, Beylerian E, Werner L, et al. The impact of an integrated electronic immunization registry and logistics management information system (EIR-eLMIS) on vaccine availability in three regions in Tanzania: A prepost and time-series analysis. Vaccine. 2019 Nov 7,

13. Nguyen NT, Vu HM, Dao SD, Tran HT, Nguyen TXC. Digital immunization registry: evidence for the impact of mHealth on enhancing the immunization system and improving immunization coverage for children under one year old in Vietnam. Mhealth [Internet]. 2017 Jul 19 [cited 2019 Jun 20],3. Available from:

https://www.ncbi.nlm.nih.gov/pmc/articles/PMC5547172/

14. Uddin MdJ, Shamsuzzaman Md, Horng L, Labrique A, Vasudevan L, Zeller K, et al. Use of mobile phones for improving vaccination coverage among children living in rural hard-to-reach areas and urban streets of Bangladesh. Vaccine. 2016 Jan 4,34(2):276-83.

15. Chen L, Du X, Zhang L, van Velthoven MH, Wu Q, Yang R, et al. Effectiveness of a smartphone app on improving immunization of children in rural Sichuan Province, China: a cluster randomized controlled trial. BMC Public Health. 2016 Aug 31,16(1):909.

16. Pan American Health Organization. Electronic Immunization Registry: Practical Considerations for Planning, Development, Implementation and Evaluation [Internet]. Washington, D.C.: PAHO, 2017 [cited 2019 Sep 6]. Available from: http://iris.paho.org/xmlui/bitstream/handle/123456789/34865/9789275119532_eng.pdf?sequence=5\&isAllowed=y

17. European Centre for Disease Prevention and Control. Designing and implementing an immunisation information system [Internet]. Stockholm: ECDC, 2018 [cited 2020 May 8]. Available from: https://repository.immregistries.org/resource/designingand-implementing-an-immunisation-information-system-a-handbook-for-those-involved-in-the-d/from/major-iis-topics/CDC/

18. World Health Organization, PATH. Planning an Information Systems Project: A Toolkit for Public Health Managers [Internet]. Seattle: PATH, 2013 [cited 2019 Sep 25]. Available from:

https://www.who.int/immunization/programmes_systems/supply_chain/optimize/planning_information_systems_project.pdf? ua $=1$

19. WHO Guideline: recommendations on digital interventions for health system strengthening [Internet]. Geneva: World Health Organization, 2019 [cited 2020 Apr 11]. Available from: https://www.who.int/publications-detail/who-guidelinerecommendations-on-digital-interventions-for-health-system-strengthening 
20. Labrique A, Vasudevan L, Weiss W, Wilson K. Establishing Standards to Evaluate the Impact of Integrating Digital Health into Health Systems. Global Health: Science and Practice. 2018 Oct 10,6(Supplement 1):S5-17.

21. The MAPS toolkit: mHealth assessment and planning for scale [Internet]. Geneva: World Health Organization, 2015 [cited 2020 Apr 13]. Available from: http://www.who.int/entity/reproductivehealth/publications/mhealth/maps/en/index.html

22. PATH [Internet]. 2020 [cited 2020 Jun 22]. Available from: https://www.path.org/

23. NEPI. Vietnam Expanded Program on Immunization (EPI) Report 2018. Hanoi, Vietnam: Vietnam Ministry of Health, 2019 Mar.

24. PATH, NEPI. Summary of Optimize Activities Conducted With Vietnam's National Expanded Programme on Immunization [Internet]. Hanoi: PATH, 2012 [cited 2020 Apr 13]. Available from: https://www.path.org/resources/summary-of-optimizeactivities-conducted-with-vietnams-national-expanded-programme-on-immunization/

25. Expanded Programme on Immunization 2010 - 2015 Comprehensive Multi Year Plan [Internet]. Tanzania: The United Republic of Tanzania Ministry of Health and Social Welfare - Tanzania Mainland, 2011 Apr [cited 2020 Jun 8]. Available from: https://bidinitiative.org/wp-content/uploads/1405554135TanzaniaComprehensivemultiyearplanfor20102015Year2011.pdf

26. Gavi, The Vaccine Alliance. Tanzania, UR [Internet]. Gavi Programmes and Impact: Country hub. 2020 [cited 2020 Jun 8]. Available from: https://www.gavi.org/programmes-impact/country-hub/africa/tanzania-ur

27. Tanzania Joint Appraisal 2019 [Internet]. United Republic of Tanzania: Gavi, the Vaccine Alliance, 2019 [cited 2020 Jun 8]. Available from: https://www.gavi.org/sites/default/files/document/2020/Tanzania\%20Joint\%20Appraisal\%202019.pdf

28. Gavi, The Vaccine Alliance. Zambia [Internet]. Gavi Programmes and Impact: Country hub. 2020 [cited 2020 Jun 8]. Available from: https://www.gavi.org/programmes-impact/country-hub/africa/zambia

29. Zambia Joint Appraisal 2018 [Internet]. Zambia: Gavi, the Vaccine Alliance, 2018 [cited 2020 Jun 8]. Available from: https://www.gavi.org/sites/default/files/document/joint-appraisal-zambia-2018pdf.pdf

30. Digital Health Atlas: Zambia HMIS [Internet]. 2020 [cited 2020 Jun 22]. Available from: https://digitalhealthatlas.org/en/-/projects/1126/published

31. BID Initiative. The BID Initiative Story: Improving health services through innovation in data quality and use [Internet]. Seattle, WA: PATH, 2018 [cited 2020 Jun 8]. Available from: https://bidinitiative.org/wpcontent/uploads/BIDStory_PRINT_English_R1_clickable.pdf

32. BID Initiative. Product Vision for the Better Immunization Data (BID) Initiative [Internet]. Seattle, WA: PATH, 2014 [cited 2020 Jun 1]. Available from: https://bidinitiative.org/wp-content/uploads/FINAL_BID-Product-Vision-09122014.pdf

33. Seymour D, Werner L, Mwansa FD, Bulula N, Mwanyika H, Dube M, et al. Electronic Immunization Registries in Tanzania and Zambia: Shaping a Minimum Viable Product for Scaled Solutions. Front Public Health [Internet]. 2019 [cited 2020 Mar 23 ],7. Available from: https://www.frontiersin.org/articles/10.3389/fpubh.2019.00218/full

34. Open Immunize (OpenIZ) [Internet]. Available from: http://openiz.org

35. Nshunju RJ, Ezekiel M, Njau P, Ulomi I. Assessing the Effectiveness of a Web-Based Vaccine Information Management System on Immunization-Related Data Functions: An Implementation Research Study in Tanzania [Internet]. Maternal and Child Survival Program, USAID, 2018 Jul. Available from: https://publications.jsi.com/JSIInternet/Inc/Common/_download_pub.cfm?id=21683\&lid=3

36. OpenSRP | Open Smart Register Platform [Internet]. [cited 2019 Feb 14]. Available from: http://smartregister.org/

37. BID Initiative. Functional Requirements document for Tanzania Immunization Registry (TImR) [Internet]. 2015 [cited 2020 Jun 9]. Available from: http://bidinitiative.org/wp-content/uploads/TimR-Functional-Requirements_.pdf

38. Titlestad OH, Seymour D. Lessons Learned in Electronic Immunization Registry Development [Internet]. Better Immunization Data (BID) Initiative. 2016 [cited 2020 Jun 22]. Available from: https://bidinitiative.org/blog/lessons-learned-in-electronicimmunization-registry-development/

39. BID Initiative, IRD, I-TECH, Ona. The catalytic potential of rapid, iterative software development: Software lessons from Pakistan, Zambia, and Kenya lay groundwork for successful electronic immunization registries [Internet]. PATH, 2020 [cited 2021 Mar 31]. Available from: https://bidinitiative.org/wp-content/uploads/CVIA_BID_Story2019_v1_rev03.pdf

40. PATH. Mobile Network Operator Partnerships in Action for Health: A Vietnam case study on mobile network operator and Ministry of Health engagement for electronic immunization registry application [Internet]. Seattle, WA: PATH, 2019 [cited 2020 Jun 10]. Available from: https://bidinitiative.org/wp-content/uploads/PartneringwMNOsIDEAL-002.pdf 
41. Mwanyika H. Capturing the End User Perspective: BID's User Advisory Group [Internet]. Better Immunization Data (BID) Initiative. 2014 [cited 2020 Jun 22]. Available from: https://bidinitiative.org/blog/capturing-the-end-user-perspective-bids-user-advisorygroup/

42. Njobvu F. User Advisory Group Established in Zambia [Internet]. Better Immunization Data (BID) Initiative. 2014 [cited 2020 Jun 22]. Available from: https://bidinitiative.org/blog/user-advisory-group-established-in-zambia/

43. Mbulo L, Mwanza R. BID partners with Catholic Medical Mission Board to expand to nine health facilities in Western Province [Internet]. Better Immunization Data (BID) Initiative. 2018 [cited 2020 Jul 11]. Available from: https://bidinitiative.org/blog/bidpartners-with-catholic-medical-mission-board-to-expand-to-nine-health-facilities-in-western-province/

44. Mvundura M, Giorgio LD, Lymo D, Mwansa FD, Ngwegwe B, Werner L. The costs of developing, deploying and maintaining electronic immunisation registries in Tanzania and Zambia. BMJ Global Health. 2019 Nov 1,4(6):e001904.

45. Mtenga H, Mphuru A, Seymour D, Werner L. The challenges of implementing a data use culture. MMS Bulletin [Internet]. 2018 Dec [cited 2020 Jun 22],(148). Available from: https://www.medicusmundi.ch/de/bulletin/mms-bulletin/digital-health/dereinsatz-digitaler-medien/the-evolution-into-government-led-implementation-of-data-quality-and-use-interventions

46. Dolan SB, Alao ME, Mwansa FD, Lymo DC, Bulula N, Carnahan E, et al. Perceptions of factors influencing the introduction and adoption of electronic immunization registries in Tanzania and Zambia: a mixed methods study. Implementation Science Communications. 2020 Mar 30,1(1):38.

47. Dang H, Dao S, Carnahan E, Kawakyu N, Duong H, Nguyen T, et al. Determinants of Scale-up From a Small Pilot to a National Electronic Immunization Registry in Vietnam: Qualitative Evaluation. Journal of Medical Internet Research. 2020,22(9):e19923.

48. World Health Organization. Request for Proposals: Immunization Registry Digital Accelerator Kit and Computable Content. World Health Organization, 2020.

49. Msangi M. A Coordinated, User-Centered Approach [Internet]. Better Immunization Data (BID) Initiative. 2015 [cited 2020 Jun 22]. Available from: https://bidinitiative.org/blog/a-coordinated-user-centered-approach/

50. Carnahan E, Ferriss E, Beylerian E, Mwansa FD, Bulula N, Lyimo D, et al. Determinants of Facility-Level Use of Electronic Immunization Registries in Tanzania and Zambia: An Observational Analysis. Global Health: Science and Practice [Internet]. 2020 Aug 19 [cited 2020 Aug 24], Available from: https://www.ghspjournal.org/content/early/2020/08/19/GHSP-D-20-00134

51. The BID Initiative. BID Initiative Lessons Learned Encyclopedia [Internet]. PATH, 2018 Jun [cited 2020 Jul 23]. Available from: https://bidinitiative.org/wp-content/uploads/FINAL_LessonsLearned_Encyclopedia_6July2018-Logo-1.pdf

52. Danovaro-Holliday MC, Ortiz C, Cochi S, Ruiz-Matus C. Electronic immunization registries in Latin America: progress and lessons learned. Rev Panam Salud Publica. 2014 Jun,35:453-7.

53. Mookherji S, LaFond A. Strategies to maximize generalization from multiple case studies: Lessons from the Africa Routine Immunization System Essentials (ARISE) project. Evaluation. 2013 Jul 1,19(3):284-303.

\section{Tables}

Table 1. Comparison of country contexts 


\begin{tabular}{|c|c|c|c|}
\hline & Vietnam & Tanzania & Zambia \\
\hline $\begin{array}{l}\text { Health } \\
\text { system }\end{array}$ & $\begin{array}{l}\text { Vietnam's health system } \\
\text { consists of five main levels: } \\
\text { national, regional, provincial, } \\
\text { district, and commune. The } \\
\text { Ministry of Health (MoH) } \\
\text { establishes policies, manages } \\
\text { national and regional } \\
\text { hospitals/institutes, and } \\
\text { provides general oversight of } \\
\text { the health system. }\end{array}$ & $\begin{array}{l}\text { Tanzania's health sector operates under } \\
\text { the Ministry of Health, Community } \\
\text { Development, Gender, Elderly, and } \\
\text { Children (MOHCDGEC) and the } \\
\text { President's Office Regional } \\
\text { Administration and Local Government } \\
\text { plays a prominent role in } \\
\text { implementations. }\end{array}$ & $\begin{array}{l}\text { Zambia's MoH provides national } \\
\text { policy and technical guidance, } \\
\text { which is then interpreted at a } \\
\text { provincial level to support } \\
\text { hospital and district health } \\
\text { management teams. }\end{array}$ \\
\hline $\begin{array}{l}\text { Immunization } \\
\text { program }\end{array}$ & $\begin{array}{l}\text { The National Expanded } \\
\text { Program on Immunization } \\
\text { (NEPI) was established in } \\
1985 \text { to provide free } \\
\text { immunization services with } \\
\text { the goal of protecting children } \\
\text { from the most common } \\
\text { infectious diseases. Despite } \\
\text { high vaccination coverage, the } \\
\text { country faced vaccine data } \\
\text { quality challenges and } \\
\text { increasing urbanization and } \\
\text { immigration made it } \\
\text { challenging to ensure every } \\
\text { child received all lifesaving } \\
\text { vaccines. }\end{array}$ & $\begin{array}{l}\text { The Immunization and Vaccine } \\
\text { Development (IVD) Program of the } \\
\text { MOHCDGEC focuses on administration, } \\
\text { M\&E, cold chain and logistics, routine } \\
\text { immunization, and training (25). } \\
\text { Despite high vaccination coverage, the } \\
\text { country faces challenges related to } \\
\text { subnational inequalities in coverage, } \\
\text { low uptake of new vaccines, inaccurate } \\
\text { target populations, and insufficient data } \\
\text { use (27). }\end{array}$ & $\begin{array}{l}\text { Since the mid-1990s, Zambia } \\
\text { has decentralized many health } \\
\text { services, including immunization, } \\
\text { to its nine provinces and } 72 \\
\text { districts. In recent years Zambia } \\
\text { has improved its immunization } \\
\text { service delivery and sustained } \\
\text { high coverage rates. However, the } \\
\text { country still faces service } \\
\text { delivery challenges including } \\
\text { highly mobile populations, } \\
\text { vaccine-preventable disease } \\
\text { outbreaks, subnational coverage } \\
\text { inequalities, and data quality } \\
\text { challenges (29). }\end{array}$ \\
\hline $\begin{array}{l}\text { Immunization } \\
\text { data and } \\
\text { reporting }\end{array}$ & $\begin{array}{l}\text { Prior to nationwide scale-up } \\
\text { of Vietnam's EIR in 2017, most } \\
\text { health facilities across the } \\
\text { country used paper-based } \\
\text { forms to record, manage, and } \\
\text { manually plan for } \\
\text { immunization delivery, stock } \\
\text { management, and reporting. } \\
\text { The paper-based forms were } \\
\text { often missing data, time } \\
\text { consuming and laborious to } \\
\text { complete, and a barrier to } \\
\text { complete reporting and } \\
\text { efficient vaccine stock } \\
\text { management (24). }\end{array}$ & $\begin{array}{l}\text { Before the launch of its EIR in } 2016 \text {, } \\
\text { Tanzania's immunization information } \\
\text { system was paper-based at the facility } \\
\text { level and digital from the district level } \\
\text { up. At the facility level, health workers } \\
\text { recorded monthly reports by hand } \\
\text { before submitting them to district } \\
\text { managers who entered digital reports } \\
\text { into the District Health Information } \\
\text { Software } 2 \text { (DHIS2) system. In addition } \\
\text { to the DHIS2, the Excel-based District } \\
\text { Vaccine Management Tool (DVD-MT) } \\
\text { and the Stock Management Tool } \\
\text { supported immunization service } \\
\text { delivery (10). }\end{array}$ & $\begin{array}{l}\text { In Zambia, facility health care } \\
\text { workers capture immunization } \\
\text { data using paper-based forms } \\
\text { and submit a monthly report of } \\
\text { aggregate data to the district } \\
\text { using the Health Information } \\
\text { Aggregation } 2 \text { (HIA2) form (11). } \\
\text { At the district, data are entered } \\
\text { into the DHIS2, the country's } \\
\text { primary health information } \\
\text { system (30). }\end{array}$ \\
\hline $\begin{array}{l}\text { Vaccination } \\
\text { coverage }\end{array}$ & $\begin{array}{l}95 \% \text { of children under } 1 \text { year } \\
\text { of age were fully vaccinated } \\
(2018)(23)\end{array}$ & $\begin{array}{l}98 \% \text { of children were vaccinated for the } \\
\text { third dose of diphtheria-tetanus- } \\
\text { pertussis vaccine (DTP3) (26) }\end{array}$ & $\begin{array}{l}90 \% \text { of children were vaccinated } \\
\text { for DTP3 in } 2018(28)\end{array}$ \\
\hline Birth cohort & 1.7 million (2018) (23) & 2.2 million (2019) (26) & 702,971 (2019) (28) \\
\hline
\end{tabular}

Table 2. Timeline of the electronic immunization registry implementation in Vietnam, Tanzania, and Zambia 


\begin{tabular}{|c|c|c|c|c|}
\hline \multirow[t]{2}{*}{ Country } & \multirow[t]{2}{*}{ System } & \multicolumn{3}{|c|}{ EIR phase } \\
\hline & & Design & Develop & Deploy \\
\hline \multirow[t]{6}{*}{ Vietnam } & ImmReg & $\begin{array}{l}3-4 \\
\text { months }\end{array}$ & 4 months & 2012: rollout to 1 district in 1 province (Ben Tre) [19 facilities] \\
\hline & Vaxtrak & $\begin{array}{l}6 \\
\text { months }\end{array}$ & 6 months & 2012: rollout in 13 provinces [30 facilities] \\
\hline & \multirow{2}{*}{$\begin{array}{l}\text { Integrated } \\
\text { ImmReg + } \\
\text { Vaxtrak }\end{array}$} & $\begin{array}{l}2 \\
\text { months }\end{array}$ & $\begin{array}{l}12 \text { months (2013- } \\
2014)\end{array}$ & $\begin{array}{l}2014-2015 \text { ( } 1.5 \text { years): ImmReg expanded to } 9 \text { districts in Ben } \\
\text { Tre province [ } 174 \text { facilities]; }\end{array}$ \\
\hline & & $(2013)$ & & $\begin{array}{l}\text { 2014-2016 (2 years): Vaxtrak scaled up to all } 63 \text { provinces } \\
\text { [200 facilities] }\end{array}$ \\
\hline & \multirow[t]{2}{*}{ NIIS } & \multirow{2}{*}{$\begin{array}{l}3-4 \\
\text { months }\end{array}$} & \multirow[t]{2}{*}{8 months } & 2016: pilot in 5 provinces $[1,649$ facilities $]$ \\
\hline & & & & 2017: deploy nationwide [ 15,000 facilities] \\
\hline \multirow[t]{4}{*}{ Tanzania } & \multirow[t]{2}{*}{ TIIS (GIIS) } & \multirow{2}{*}{$\begin{array}{l}\text { 7-8 } \\
\text { months } \\
(2014)\end{array}$} & \multirow{2}{*}{$\begin{array}{l}6 \text { months } \\
(2015)\end{array}$} & \multirow[t]{2}{*}{ 2015-2017: rollout in Arusha Region [285 facilities] } \\
\hline & & & & \\
\hline & \multirow[t]{2}{*}{ TImR (OpenIZ) } & \multirow{2}{*}{$\begin{array}{l}2-3 \\
\text { months } \\
(2015)\end{array}$} & \multirow{2}{*}{$\begin{array}{l}9 \text { months } \\
(2016-2017)\end{array}$} & July 2017-2021: rollout in 15 regions [3,736 facilities] \\
\hline & & & & $\begin{array}{l}\text { 2021: plans to scale nationwide by the end of the year }[\sim 6,000 \\
\text { facilities] }\end{array}$ \\
\hline \multirow[t]{5}{*}{ Zambia } & \multirow{2}{*}{$\begin{array}{l}\text { DHIS2 patient } \\
\text { tracker }\end{array}$} & \multirow{2}{*}{$\begin{array}{l}9 \\
\text { months } \\
(2014- \\
2015)\end{array}$} & 12 months & \multirow{2}{*}{$\begin{array}{l}\text { N/A (was introduced in } 6 \text { pilot facilities for testing during the } \\
\text { development phase) }\end{array}$} \\
\hline & & & (2015-2016) & \\
\hline & \multirow[t]{3}{*}{$\begin{array}{l}\text { ZEIR } \\
\text { (OpenSRP) }\end{array}$} & $\begin{array}{l}5 \\
\text { months }\end{array}$ & $\begin{array}{l}3 \text { months: initial } \\
\text { release; }\end{array}$ & $\begin{array}{l}\text { 2017-2018 (13 months): rollout in Southern Province [320 } \\
\text { facilities] and a subset of Western Province [9 facilities] }\end{array}$ \\
\hline & & \multirow[t]{2}{*}{$(2016)$} & $\begin{array}{l}6 \text { months: version } \\
\text { for broader rollout }\end{array}$ & \multirow[t]{2}{*}{$\begin{array}{l}\text { 2021: plans to 'go live' in all facilities in Western Province [ } 281 \\
\text { facilities] }\end{array}$} \\
\hline & & & $(2017)$ & \\
\hline
\end{tabular}

Table 3. Summary of recommendations 


\section{Recommendations to countries implementing an EIR}

- Plan for an iterative EIR development process, starting with the minimum viable product requirements and adapting or expanding the EIR over time. Prepare for multiple pilots or iterations to strengthen the system over the long term.

- Include end-users from the start to inform the system requirements, support pilot testing, and provide routine feedback to inform incremental system updates.

- Establish an interdisciplinary team with experience in leadership, technology, and immunization to oversee the EIR design, development, and deployment. Include national government/MoH staff to ensure country ownership, sustainability, and alignment with national strategies and standards.

- Formalize team roles, responsibilities, and commitments of this interdisciplinary team through an MOU or other written agreement.

- Ensure funding to sustain and maintain the EIR system, including all recurring costs and software enhancements and maintenance.

- Capture costs on EIR design, development, and deployment to fill existing evidence gaps and test the hypothesis that there are economies of scale and cost savings from adapting existing systems.

- Develop long-term plans for ongoing system maintenance, updates, and end user support. This should include identifying a partner based locally that can provide ongoing system maintenance and support beyond the initial deployment.

- Consider sustainability and scale from the beginning by establishing government ownership; planning for long-term financing, system maintenance, and user support; and preparing for the transition from the legacy tools to new tools.

\section{Figures}

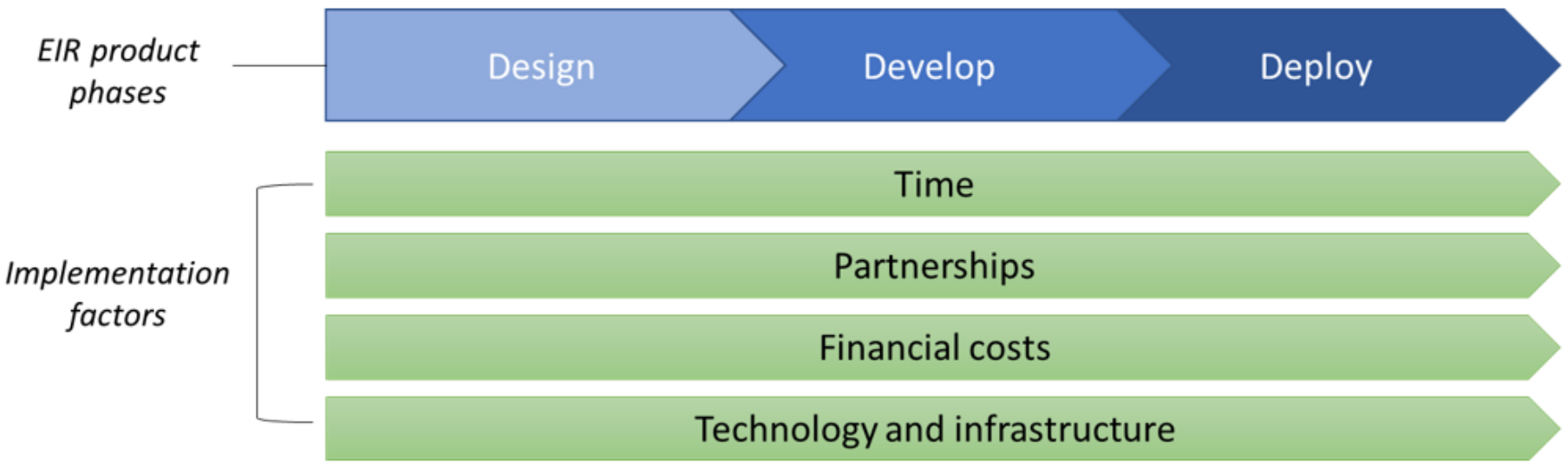

Figure 1

Conceptual Framework

\section{Supplementary Files}

This is a list of supplementary files associated with this preprint. Click to download.

- SRQRchecklist.docx 